\title{
Quality of life and chronic disease in patients receiving primary health care
}

\author{
Olinda Preto $^{\mathrm{a}}$, Odete Amaral ${ }^{\mathrm{b} *}$, João Duarte ${ }^{\mathrm{b}}$, Cláudia Chaves $^{\mathrm{b}}$, Emília \\ Coutinho $^{\mathrm{b}}$, Paula Nelas ${ }^{\mathrm{b}}$ \\ *Corresponding author: Odete Amaral, mopamaral@gmail.com \\ ${ }^{a}$ Family Health Unit of Viseu. Primary Health Care - Health Centers Grouping Dão Lafões. Viseu. Portugal \\ ${ }^{b *}$ Superior Health School, Polytechnic Institute of Viseu, Rua D. João Crisóstomo Gomes de Almeida, $n^{\circ} 102,3500-843$ Viseu, \\ Portugal,mopamaral@gmail.com
}

\begin{abstract}
http://dx.doi.org/10.15405/epsbs.2016.07.02.21

Problem Statement: Chronic disease entails physical, psychological and social issues with a decrease in the quality of life. The assessment of QoL has been applied as indicator in patients with chronic diseases.

Research Questions: What is the quality of life in patients with chronic disease? What are the socio-demographic variables that influence the quality of life in patients?

Purpose: To assess the quality of life in patients suffering from chronic disease and identify socio-demographic variables which influence the quality of life of patients suffering from chronic disease.

Research Methods: We conducted a cross-sectional analytical study using a sample composed of 228 users (134 females) from a Family Health Unit in the municipality of Viseu. Data collection was made by means of a questionnaire, consisting of sociodemographic variables, the SF-12 scale and the existence of chronic disease was assessed through the questions - "Do you currently suffer from any chronic disease?"; "If so, which one(s)?".

Findings: The most common chronic diseases were hypertension (59.9\%). Female patients with a chronic disease reported worse physical functioning, role-physical and role-emotional; increased bodily pain and better quality of life regarding general health. Male patients showed worse role-physical, increased bodily pain and vitality. Sociodemographic variables which were associated with quality of life were area of residence, academic qualifications and work situation.

Conclusion: Chronic disease affects quality of life negatively. Quality of life in both patients groups was associated with socio-demographic variables. Health-related quality of life is an essential issue and should be considered as a priority in health policies.
\end{abstract}

(C) 2016 Published by Future Academy www.FutureAcademy.org.uk

Keywords: Quality of life, chronic disease, primary health care.

\section{Introduction}

Population-ageing is a global reality and Portugal is also an example of this fact as one of the European Union countries with the highest rate of ageing population (Nicola, 2011). Demographic and 
epidemiological changes generate changes in health standards, increase in prevalence, incidence and comorbidities of chronic diseases, resulting in a decreased quality of life. The population groups in greater need of support, health care and interventions are those with chronic illnesses and the elderly. Chronic diseases are currently a major health issue, due to their scope and repercussions, particularly a decreased quality of life arising from increased health technology, life expectancy and lifestyle changes (Azevedo, Silva, Tomasi and Quevedo 2013, Capilheira and Santos 2011). According to data from the World Health Organization (WHO), between 2002 and 2003 the increase in chronic diseases reached a high level, and it is estimated that, by $2020,80 \%$ of the global burden of disease in developing countries will be due to chronic health problems. The majority of chronic diseases hold the potential to worsen the overall health of patients by limiting their capacity to live well, limit the functional status, productivity and Health Related Quality of Life (HRQoL) and are a major contributor to health care costs (Megari 2013). Primary health care are vital for the promotion of health, prevention of disease and factors related thereto, in addition to being the gateway to the National Health System. This context includes chronic diseases, because of a planned importance of implementing strategies for the reduction of the prevalence and risk factors directly related to changes in lifestyles and to quality of life (Capilheira and Santos 2011).

Historically, one of the widely accepted definitions of chronic disease was the one proposed in 1957 by the Commission on Chronic Illness at Cambridge, which included all diseases with one or several of the following features - permanent, generating residual incapacity/disability, are caused by irreversible pathological changes, require special training of the patient towards recovery, or may require extended monitoring, observation or care provision periods (Kuller Tonascia 1971). In turn, WHO subscribes to the definition of chronic disease, considering that, in general, "diseases are slow in progression, long in duration, and they require medical treatment (WHO 2013). Chronic diseases and conditions - such as heart disease, stroke, cancer, diabetes, obesity, and arthritis - are among the most common, costly, and preventable of all health problems (National Center for Chronic Diseases and Health Promotion 2009). In Europe, the chronic diseases with the highest prevalence are heart disease, cancer, respiratory disease, diabetes and mental health problems (WHO 2005).

The complexity and scope of the issue which is intrinsic to the experience of the disease's chronicity have allowed for the development of research aimed at examining the impact of the said condition in the quality of life of people suffering from a chronic disease. Quality of life is a broad multidimensional concept that usually includes subjective evaluations of both positive and negative aspects of life (WHOQOL Group 1998). Assessing quality of life is complex due to the fact that there is no universally accepted definition. Nevertheless, quality of life can be defined as "an individual's perception of their position in life in the context of the culture and value systems in which they live and in relation to their goals, expectations, standards and concerns" (WHO 1995). This concept includes the person's physical health, psychological state, level of independence, social relationships, personal beliefs and relationship to salient features of surrounding environment (Azevedo et al 2013, Fleck 2008). It is generally accepted that HRQoL is a multidimensional construct that consists of at least three broad domains - physical, psychological, and social functioning - that are affected by one's disease and/or treatment (WHOQOL Group 1998). As well as, the QoL concept is currently embraced by three 
http://dx.doi.org/10.15405/epsbs.2016.07.02.21

eISSN: 2357-1330 / Corresponding Author: Odete Amaral

Selection and peer-review under responsibility of the Organizing Committee of the conference

major domains of science: economics, social sciences and medicine. In the biomedical and nursing fields, QoL has become a key concept for evaluating the quality and outcome of health care, especially in chronic disease. The diagnosis of a chronic disease on an individual generally means the beginning of a decline in the quality of life. In the last 30 years, health-related quality of life has become an important outcome measure for patients with chronic diseases. From 1973 onwards, health associated with quality of life has been widely used to assess efficacy and cost-effectiveness results of new treatment strategies (Testa and Simonson 1996, Xie et al. 2014).

Assessing and monitoring the quality of life of individuals suffering from a chronic disease are important in the planning of intervention strategies, given that it provides relevant information on the patient, enabling the identification of his/her priorities and subsidizing health programs towards the implementation of effective action and, therefore, offer a better quality of life to health care users (Kluthcovsky and Kluthcovsky 2009). HRQoL is an important measure to evaluate the impact of a disease and the effects of medical intervention, thus, an improvement in HRQoL is considered to be an essential primary outcome and determinant of therapeutic benefit.

QoL is a subjective concept, and research also has various general tools to assess it. Several measures have been used to assess HRQoL and related concepts of functional status. Among them are the Medical Outcomes Study Short Forms (SF-12 and SF-36), the Sickness Impact Profile, and the Quality of Well-Being Scale (Centers for Disease Control and Prevention).

Scientific evidence shows that the major factors associated with the quality of life are gender, age, unhealthy habits (smoking, drinking, among others), marital status and poverty (Lim, Jin and Ng 2012, Fortin at al. 2006). The main chronic diseases mentioned by the individuals who participated in the International Quality of Life Assessment (IQOLA) Project were hypertension, allergies and arthritis (Alonso et al. 2004). A study conducted on a sample of 5345 people showed that patients with chronic diseases (hypertension, diabetes, coronary heart disease and stroke) had a decrease in the quality of life $(\mathrm{p}<0.001)$ (Cao et al. 2012). The same study also concluded that the risk of a decreased quality of life in patients suffering from chronic diseases - hypertension, diabetes, coronary heart disease and stroke was $\mathrm{RR}=1.686,95 \% \mathrm{CI}: 1.519-1.871 ; \mathrm{RR}=1.725,95 \% \mathrm{CI}: 1.502-1.981 ; \mathrm{RR}=1.869,95 \% \mathrm{CI}: 1.663-2.099$ and $\mathrm{RR}=1.759,95 \% \mathrm{CI}: 1.474-2.089$, respectively (Cao et al. 2012). In Brazil, a study conducted in 2009 on a sample of 1081 people aged over 14 pointed that the existence of a chronic disease decreased the quality of life (Azevedo et al 2013). Moreover, it mentioned that the female gender and aging were related to the decrease in the quality of life and that the individuals who cohabited with a partner had a better quality of life (Azevedo et al 2013).

In clinical practice, when patients suffering from chronic diseases are properly monitored, the perception of quality of life can be preserved (Instituto Nacional de Saúde Dr. Ricardo Jorge 2005).

Therefore, the goals of this study were to assess the quality of life in patients suffering from a chronic disease and establish the socio-demographic variables which have an impact on the quality of life of patients with a chronic disease. 


\section{Research Methods}

We carried out a cross-sectional analytical study on a non-probability convenience sample.

Data were collected by means of a face-to-face questionnaire and answered by patients in the waiting room of a Family Health Unit (FHU) in the municipality of Viseu. The questionnaire was divided into three sections: the first concerned socio-demographic characterization, carried out using the variables gender, age, place of residence, marital status, academic qualifications and work situation; the second assessed the existence of a chronic disease and was composed of the questions "Do you suffer from any chronic disease?" and "If so, which one(s)?"; lastly, the third section was composed of the Short-Form Health Survey 12 Item (SF-12) Scale, aimed at assessing the health-related quality of life. The SF-12 consists of a generic measure of the health status and has been validated for the Portuguese population by the Centro de Estudo e Investigação em Saúde of the University of Coimbra, based on the Portuguese version of the Medical Outcomes Study Short Form 36 Health Survey Instrument (Ferreira 1998). This scale assesses the individual perception of health-related quality of life by means of 12 questions grouped into eight dimensions (physical functioning, physical appearance, pain, general health, vitality, social functioning, emotional functioning and mental health) with an impact on the quality of life, taking into account self-perception of health elements in the previous four weeks. Each item has a set of answers arranged according to a Likert-type scale, with 3 or 5 points. Dimensions can be grouped in two components: physical and mental. Each component includes 6 questions. Questions which measure physical functioning, physical appearance, pain and general health have a higher correlation with the physical component, whereas vitality, social functioning, emotional domain and mental health are more correlated with the mental component. As for general health, vitality and social functioning, these show a high correlation with both scores of the questionnaire. The scale scores range from zero to one hundred and higher figures are associated with a better quality of life.

Data collection was performed between January and March 2014. The final sample was composed of 228 patients of the FHU, $134(58.8 \%)$ of whom were female. The mean age was $52.01 \pm 14.57$ years (with a minimum age of 18 and maximum age of 85 years), where the mean age was more significant for males (57.95 \pm 12.27 vs. $47.84 \pm 14.65)$.

According to table 1, we observe that distribution by age in both genders has a percentage of $38.6 \%$ for $\leq 50$ years; $41.7 \%$ for those between 51 and 65 years, and $19.7 \%$ for those $\geq 66$ years. The highest percentage of male patients live in a village (51.1\%), whereas most female patients mentioned that they lived in a city (55.7\%). As for marital status, $73.7 \%$ of patients are married or are joined in a civil partnership; $17.4 \%$ are separated/divorced/widows and $8.9 \%$ are single. As regards academic qualifications, $39.5 \%$ patients of the total sample have completed primary and lower secondary education, $33.3 \%$ have completed secondary/higher education and $6.1 \%$ do not know how to read or write/sign their name. The highest percentage of female patients (45.5\%) are employed; 30.6\% are unemployed/students; $14.2 \%$ retired and $9.7 \%$ are housewives. As for males, $41.5 \%$ are retired; $36.2 \%$ work; $12.8 \%$ are house husbands and $9.6 \%$ are unemployed or students. 
The coordinator of the FHU was asked for permission to apply the questionnaires in the waiting room of one FHU in the municipality of Viseu. After the corresponding permission was granted, data were collected considering the following inclusion criteria: being a user of the FHU, being present in the waiting room on the dates that data were collected and showing an interest in participating in the study. Confidentiality and anonymity of data were ensured to participants.

Data collected were entered into a database and processed using the Statistical Package of the Social Sciences (SPSS) software, version 21.0. Central tendency (average) and dispersion (standard deviation) measures were calculated. Prevalences were calculated and expressed in percentages, using a $5 \%$ significance level. In order to compare the distributions of continuous variables, the T Student test for independent samples and the Kruskal-Wallis test were used.

Table 1. Socio-demographic characterization of the sample

\begin{tabular}{|c|c|c|c|c|c|c|}
\hline & \multicolumn{2}{|c|}{ Female } & \multicolumn{2}{|c|}{ Male } & \multicolumn{2}{|c|}{ Total } \\
\hline & $\begin{array}{c}\mathbf{n} \\
(134)\end{array}$ & $\begin{array}{c}\mathbf{\%} \\
(58.8) \\
\end{array}$ & $\begin{array}{c}\mathbf{n} \\
(94)\end{array}$ & $\begin{array}{c}\mathbf{\%} \\
(41.2) \\
\end{array}$ & $\begin{array}{c}\mathbf{n} \\
(228)\end{array}$ & $\begin{array}{c}\mathbf{\%} \\
(100.0) \\
\end{array}$ \\
\hline \multicolumn{7}{|l|}{ Age (years) } \\
\hline$\leq 50$ years & 69 & 51.5 & 19 & 20.2 & 88 & 38.6 \\
\hline $51-65$ years & 50 & 37.3 & 45 & 47.9 & 95 & 41.7 \\
\hline$\geq 66$ years & 15 & 11.2 & 30 & 31.9 & 45 & 19.7 \\
\hline \multicolumn{7}{|l|}{ Area of residence } \\
\hline Village & 48 & 36.6 & 46 & 51.1 & 94 & 42.5 \\
\hline Town & 10 & 7.6 & 14 & 15.6 & 24 & 10.9 \\
\hline City & 73 & 55.7 & 30 & 33.3 & 103 & 46.6 \\
\hline \multicolumn{7}{|l|}{ Marital status } \\
\hline Single & 16 & 11.9 & 4 & 4.4 & 20 & 8.9 \\
\hline Married/civil partnership & 91 & 67.9 & 74 & 82.2 & 165 & 73.7 \\
\hline Divorced/separated/widow & 27 & 20.2 & 12 & 13.4 & 39 & 17.4 \\
\hline \multicolumn{7}{|l|}{ Academic qualifications } \\
\hline $\begin{array}{l}\text { Does not know how to read or } \\
\text { write/how to sign their name }\end{array}$ & 7 & 5.2 & 7 & 7.4 & 14 & 6.1 \\
\hline Lower basic education & 34 & 25.4 & 42 & 44.7 & 76 & 33.3 \\
\hline $\begin{array}{l}\text { Primary and lower secondary } \\
\text { education ( } 5 \text { th-12th grades) }\end{array}$ & 55 & 41.0 & 35 & 37.2 & 90 & 39.5 \\
\hline Secondary/higher education & 38 & 28.4 & 10 & 10.6 & 48 & 21.1 \\
\hline \multicolumn{7}{|l|}{ Work situation } \\
\hline Working & 61 & 45.5 & 34 & 36.2 & 95 & 41.7 \\
\hline Unemployed/student & 41 & 30.6 & 9 & 9.6 & 50 & 21.9 \\
\hline Retired & 19 & 14.2 & 39 & 41.5 & 58 & 25.4 \\
\hline Housewife/house husband & 13 & 9.7 & 12 & 12.8 & 25 & 11.0 \\
\hline
\end{tabular}

\section{Findings}

Most patients of the total sample suffer from a chronic disease (65.9\%, $\mathrm{n}=147$ patients), women more significantly $(51.0 \%$ vs. $49.0 \%$; $<0.001)$. We observed that the most common chronic diseases were hypertension (59.9\%); hypertension + diabetes (15.6\%), diabetes $(6.1 \%)$ and $18.4 \%$ mentioned other chronic illnesses. As regards quality of life depending on gender, we found significant differences 
between the bodily pain and role-emotional dimensions, where women have higher averages for bodily pain $(2.40 \pm 1.20$ vs. $2.00 \pm 1.03 ; \mathrm{p}=0.03)$ and men for role-emotional $(3.18 \pm 0.84$ vs. $2.90 \pm 0.84 ; \mathrm{p}=0.05)$ (Table 2)

Table 2 - Quality of life (SF-12) and gender

\begin{tabular}{|c|c|c|c|}
\hline & \multicolumn{2}{|c|}{ Gender } & \multirow[b]{3}{*}{$p$} \\
\hline & Female & Male & \\
\hline & $\bar{X} \pm \mathrm{SD}$ & $\bar{X} \pm \mathrm{SD}$ & \\
\hline $\mathrm{PC}$ & $50.0 \pm 12.0$ & $48.8 \pm 12.2$ & 0.57 \\
\hline $\mathrm{MC}$ & $48.0 \pm 12.7$ & $51.1 \pm 15.8$ & 0.20 \\
\hline $\mathrm{PF}$ & $4.36 \pm 1.47$ & $4.69 \pm 1 \pm 34$ & 0.15 \\
\hline $\mathrm{RP}$ & $3.11 \pm 0.91$ & $3.19 \pm 0.87$ & 0.57 \\
\hline $\mathrm{BP}$ & $2.40 \pm 1.20$ & $2.00 \pm 1.03$ & 0.03 \\
\hline $\mathrm{GH}$ & $3.63 \pm 0.91$ & $3.43 \pm 0.96$ & 0.20 \\
\hline MH & $51.1 \pm 15.6$ & $59.5 \pm 14.4$ & 0.21 \\
\hline RE & $2.90 \pm 0.84$ & $3.18 \pm 0.84$ & 0.05 \\
\hline $\mathrm{SF}$ & $3.84 \pm 1.00$ & $3.97 \pm 1.03$ & 0.42 \\
\hline V & $2.86 \pm 1.03$ & $2.69 \pm 1.14$ & 0.31 \\
\hline
\end{tabular}

According to table 3, quality of life and presence or absence of stratified chronic disease according to gender, we find that female patients suffering from a chronic disease have lower averages, i.e. mention a worse mental component as regards quality of life $(48.01 \pm 12.74$ vs. $53.33 \pm 13.55$; $\mathrm{p}=0.02)$, worse physical functioning and role-physical $(\mathrm{p}<0.01, \mathrm{p}=0.03$ respectively) and worse role-emotional $(<0.001)$. On the other hand, female patients suffering from a chronic disease mention having more bodily pain and better general health $(\mathrm{p}=0.01 ; \mathrm{p}<0.01$, respectively).

Table 3. Quality of life (SF-12) and chronic disease

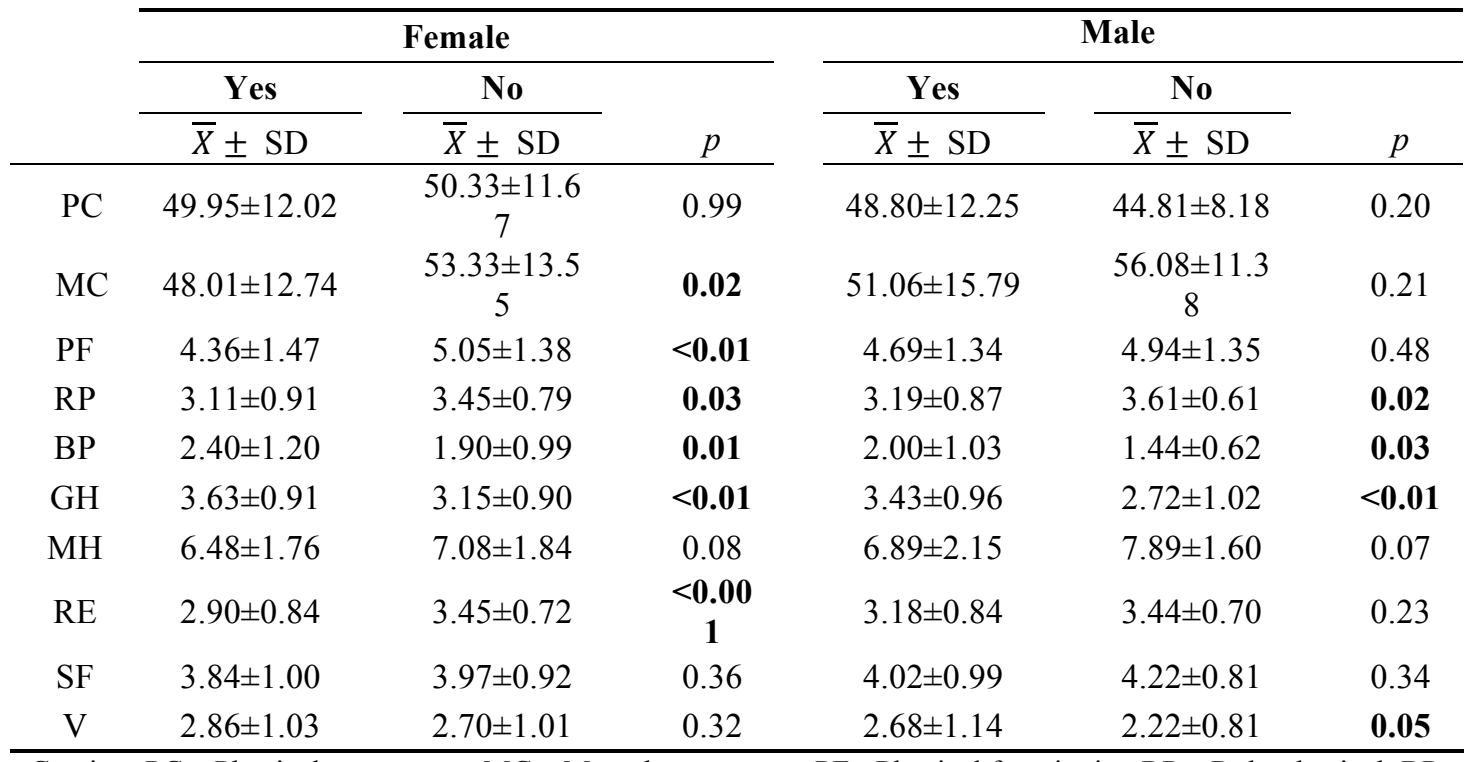

Caption: PC - Physical component; MC - Mental component; PF - Physical functioning RP - Role-physical; BP - Bodily pain; GH - General health; MH - Mental health; RE - Role-emotional; SF - Social functioning; V Vitality. 
As for the male gender, and according to the findings by dimension, we ascertain that men with a chronic disease have higher averages in bodily pain, general health and vitality $(\mathrm{p}=0.03 ; \mathrm{p}<0.01$; $\mathrm{p}=0.05$, respectively). Men without a chronic disease have a better role-physical $(\mathrm{p}=0.02)$.

As for socio-demographic variables associated with quality of life, we observe that age and marital status were not statistically significant. As regards the domain of the place of residence, we observe that there are no statistical differences in quality of life, except for the "vitality" dimension in which patients living in the city have more vitality $(2.98 \pm 1.05$ vs. $2.49 \pm 1.07 ; \mathrm{p}<0.01)$. As regards academic qualifications, in the "physical functioning" dimension we observe that as academic qualifications increase so do average orderings (can neither read nor write, but can sign $=59.67$; lower basic education $=65.71$; primary and lower secondary education $=77.14$; middle school or higher education $=91.07 ; \mathrm{p}=0.04)$. We can apply the same analysis to the "role-emotional" dimension, increase in academic qualifications is associated with the increase in average orderings, i.e. the role-emotional of patients increases (can neither read nor write, but can sign $=67.00$; lower basic education $=61.93$; primary and lower secondary education $=81.34$; middle school or higher education $=88.00 ; \mathrm{p}=0.02$ ).

When examining the work situation and quality of life, we find significant differences in the dimensions "physical functioning", "role-physical", "mental health", and in the mental component of the SF-12 scale. Therefore, in the "physical functioning" dimension patients who are working show higher averages (working $=5.00 \pm 1.25$; unemployed $=4.29 \pm 1.42$; retired $=4.38 \pm 1.45 ; \mathrm{p}=0.03$ ). In the "role-physical" dimension the higher averages also correspond to employed individuals working = $3.41 \pm 0.79$; unemployed $=3.26 \pm 0.89$; retired $=2.94 \pm 0.91 ; \mathrm{p}=0.02$ ). As for "bodily pain", lower averages were found in the employed individual's category (working $=1.73 \pm 0.89$; unemployed = $2.48 \pm 1.23$; retired $=2.43 \pm 1.20 ; \mathrm{p}<0.01$ ). Employed patients mentioning a better role-emotional and mental health show the best emotional performance and mental health (working $=3.35 \pm 0.76$; unemployed $=2.93 \pm 0.89 ;$ retired $=2.92 \pm 0.90 ; \mathrm{p}=0.02$ ) and (working $=7.19 \pm 1.86$; unemployed $=$ $6.29 \pm 2.00$; retired $=6.90 \pm 1.95 ; \mathrm{p}<0.01)$, respectively. In the scale's mental component, unemployed individuals show the worst averages (working $=53.08 \pm 13.47$; unemployed $=46.54 \pm 12.28$; retired $=$ $51.88 \pm 15.23 ; \mathrm{p}<0.01)$.

\section{Discussion}

Chronic disease is a very common clinical problem in elderly patients and is associated with increased morbidity and mortality.

As life expectancy continues to improve worldwide, there is a rising prevalence of comorbidities and risk factors predisposing to a high burden of chronic disease in population. Thus, this study intends to assess quality of life in primary health care users with a chronic disease and identify sociodemographic variables which have an impact on users' quality of life. The overall concept of quality of life is considered as an advantageous complement to the notions of health and functional status (WHOQOL Group 1998). Therefore, an optimal health assessment may include measuring physical health, functioning of the individual in physical, social and psychological domains, as well as measuring quality of life ((WHOQOL Group 1998). In clinical practice, effective management of chronic diseases 
is important to maintain the HRQoL value. HRQoL can potentially provide relevant information on the perception of the weight of chronic disease on individuals.

In this study, the most prevalent chronic diseases were hypertension, diabetes and hypertension + diabetes. Chronic diseases are highly prevalent in Portugal and in Europe. A study conducted by the Instituto Nacional de Saúde in 2005 on the predominance of some chronic diseases showed a selfreported prevalence of rheumatic diseases of $24 \%$, overweight in $15.4 \%$, arterial hypertension of $18 \%$, asthma/asthmatic bronchitis of 9\% and diabetes of 5\% (Instituto Nacional de Saúde Dr. Ricardo Jorge 2005). In England, 32\% of men and 30\% of women, with aged 16 years or over, have hypertension. The equivalent figures for Scotland are $33 \%$ of men and $28 \%$ of women. In Northern Ireland, $19 \%$ of men and $27 \%$ of women reported having been diagnosed with high blood pressure (Maryon-Davis and Stewart 2005). Arterial hypertension is a serious public health issue, and one of the main causes of mortality and morbidity in developed countries, especially when it is ignored or inadequately controlled/without adherence to the treatment regime (Macedo et al. 2007). It is estimated that there are about 972 million hypertensive individuals across the world, and in Portugal the estimated prevalence of hypertensive individuals is $42.1 \%$ (Oliveira Frédéric et al. 2007). A study carried out in Castelo Branco on a sample of 402 individuals from both genders (61.2\% females and $38.8 \%$ males) aged 18 or over showed that the prevalence of hypertension was $62.4 \%$, (61.4\% women and $38.6 \%$ men $)$ and of 23.1\% as regards diabetes (Simões et al. 2011). Data from Portugal point to a national prevalence of diabetes between $5 \%$ and $9.9 \%$, with $9.1 \%$ for the central region (Vaz, Santos, and Carneiro 2005; Perdigão et al. 2009) and in Europe there is a prevalence of 7.8\% (Vaz, Santos, and Carneiro 2005).

As for quality of life and chronic disease, most studies agree that chronic diseases are associated with a decrease in the HRQoL (Fortin at al.2006; Cao et al. 2012; Azevedo et al. 2013). This study confirmed that chronic diseases have an adverse effect on the HRQoL. A study conducted on a sample of 5345 individuals showed that patients suffering from chronic diseases (hypertension, diabetes, coronary heart disease and stroke) have a decreased quality of life ( $\mathrm{p}<0.001)$ (Cao et al. 2012). Another study conducted on Chinese adults showed that the HRQoL score was significantly negatively associated with older age, being female, having diabetes, having hypertension, having a history of chronic respiratory disease, stroke, kidney disease, and myocardial infarction, but positively associated with higher educational level, having administrative job, marital status (all p<0.05) (Xie et al. 2014). It is well known that elderly women have lower QoL than their male counterparts (Gargano and Reeves 2007; Kim, Lee, and Kim 2012). In this research, age was not associated with quality of life on individuals suffering from a chronic disease. Women suffering from a chronic disease reported a worse mental component as regards quality of life, worse physical functioning, physical performance, emotional functioning and higher averages in the domains of bodily pain and general health. Male patients suffering from a chronic disease mentioned higher averages in terms of bodily pain, general health and vitality. Men not suffering from a chronic disease had a better physical performance. Out of the remaining sociodemographic variables examined, the place of residence, academic qualifications and work situation were associated with the components/dimensions in the SF-12 scale. As for the place of residence, we observe that individuals with a chronic disease and living in the city have more "vitality". Higher academic qualifications were related to better physical functioning and emotional 
functioning. The work situation showed that 'employed' individuals suffering from a chronic disease have better 'physical functioning', 'physical performance', 'emotional functioning', report more 'bodily pain' and have a worse 'mental health'.

Quality of life emerged in the last decades as an essential tool to measure the impact of chronic diseases, as well as that of therapeutic interventions, associated with overall health indicators, such as death rate. HRQoL can be assessed by validated instruments, such as the Short Form Health Survey (SF-36), SF-12.

Chronic diseases cause changes in the routine and activity planning, especially in the case of incapacitating diseases, in which the individual stops carrying out his or her daily activities. The recurrent crises and the physical, emotional and financial overload lead the individual to deal with insecurity and social dilemmas, in addition to heavy expenses, which generate other chronic conditions that can affect the whole family. People are living longer with chronic illnesses such as hypertension and diabetes.

These findings are important for the knowledge and assessment of the HRQOL in patients with a chronic disease under primary health care and to subsequently develop and support programs which minimize the effects of chronic disease, preserve the ability of individuals and improve quality of life. Thus, the inclusion of HRQOL measures in clinical assessment may improve diagnostic accuracy to improve clinical outcomes and better target public health promotions.

\section{Conclusions}

This study confirmed that chronic diseases adversely affect the quality of life of Portuguese patients. We concluded that the most common chronic diseases in this study were hypertension and diabetes and that sociodemographic variables related thereto were gender, place of residence, academic qualifications and work situation. Conclusively, as the number of people with chronic diseases is increasing it is necessary for them gain an optimal HRQoL.

\section{Acknowledgements}

The present studywas funded by the Portuguese Foundation for Science and Technology through the project PEst-OE/CED/UI4016/2014 and by the Center for Studies in Education, Technologies, and Health.

\section{References}

Nicola, R. (2011). Envelhecimento demográfico - Dinâmicas da população e das famílias. http://www.updigital.pt/clientes/serga/website/userfiles/files/Relat\%C3\%B3rio\%20sobre\%20Demografia $\% 20 \mathrm{e} \% 20$ Projec $\%$ C3\%A7\%C3\%B5es\%20Final\%20sem\%20imagens.pdf.

Azevedo, A.L.S., Silva, R.A., Tomasi, E., \& Quevedo, L.A. (2013). Doenças crônicas e qualidade de vida na atenção primária à saúde. Cadernos de Saúde Pública; 29(9):1774-1782. http://www.scielo.br/pdf/csp/v29n9/a17v29n9.pdf.

Capilheira, M., \& Santos, I.S. (2011). Doenças crónicas não transmissíveis: desempenho no cuidado médico em atenção primária à saúde no sul do Brasil. Cadernos de Saúde Pública; 27:1143-1153.

Megari, K (2013). Quality of life in chronic disease patients. Health Psychology Research; 1(e27): 141-148.

Kuller, L., \& Tonascia, S. (1971). A follow-up study of the Commission on Chronic Illness morbidity survey in Baltimore. IV. Factors influencing mortality from stroke and arteriosclerotic heart disease (1954-1967). Journal of Chronic Diseases 24(2):111-124.

World Health Organization. Noncommunicable diseases. Geneva, 2013. Available from http://www.who.int/mediacentre/factsheets/fs355/en/. 
National Center for Chronic Diseases and Health Promotion (CDC). The Power of Prevention Chronic disease the public health challenge of the 21st century. 2009. Available from http://www.cdc.gov/chronicdisease/pdf/2009-power-of-prevention.pdf

World Health Organization. Preventing chronic disease: a vital investment - WHO global report. Geneva, 2005. Available from http://www.who.int/chp/chronic_disease_report/en.

The WHOQOL Group 1998. The World Health Organization Quality of Life Assessment (WHOQOL): development and psychometric properties. Social Science \& Medicine 46(12):1569-1585.

World Health Organization (1995). The World Health Organization Quality of Life Assessment (WHOQOL): position paper from the World Health Organization. Social Science \& Medicine. 41(10):403-409.

Fleck, M.P.A. (2008). A avaliação de qualidade de vida: guia para profíssionais da saúde. Porto Alegre: Editora Artmed.

Testa, M.A., \& Simonson, D.C. (1996). Assessment of Quality-of-Life Outcomes. New England Journal of Medicine; 334: 835-840.

Xie, G., Laskowitz, D.T., Turner, E.L., Egger, J.R., Shi, P., Ren, F. ... Wu, Y. (2014). Baseline Health-Related Quality of Life and 10-Year All-Cause Mortality among 1739 Chinese Adults. PLoS ONE; 9(7):1-9. doi:10.1371/journal.pone.0101527.

Kluthcovsky, A.C., \& Kluthcovsky, F.A. (2009). O WHOQOL-Bref, um instrumento para avaliar qualidade de vida: uma revisão sistemática. Revista de Psiquiatria do Rio Grande do Sul; 31(3) Suppl 0:1-12.

Centers for Disease Control and Prevention. Health-Related Quality of Life (HRQOL). http://www.cdc.gov/hrqol/concept.htm

Lim, L., Jin, A.Z., \& Ng, T.P. (2012). Anxiety and depression, chronic physical conditions, and quality of life in an urban population sample study. Social Psychiatry and Psychiatric Epidemiology; 47(7):1047-1053.

Fortin, M., Bravo, G., Hudon, C., Lapointe, L., Almirall, J., Dubois, M.F., \& Vanasse, A. (2006). Relationship between multimorbidity and health-related quality of life of patients in primary care. Quality of Life Research; 15(1):83-91.

Alonso, J.1., Ferrer, M., Gandek, B., Ware, J.E., Aaronson, N.K., Mosconi, P., Rasmussen, N.K. ... Leplège, A. (2004). IQOLA Project Group. Health-related quality of life associated with chronic conditions in eight countries: results from the International Quality of Life Assessment (IQOLA) Project. Quality of Life Research; 13(2):283-298.

Cao, Y., Tang, X., Yang, L., Li, N., Wu, Y.Q., Fan, W.Y., Liu, J.J. ... Hu, Y.H. (2012). [Influence of chronic diseases on health related quality of life in middle-aged and elderly people from rural communities: application of EQ-5D scale on a Health Survey in Fangshan, Beijing]. Zhonghua Liu Xing Bing Xue Za Zhi; 33(1):17-22

Instituto Nacional de Saúde Dr. Ricardo Jorge, Observatório Nacional de Saúde (ONSA). Uma observação sobre a prevalência de algumas doenças crónicas, em Portugal Continental. Lisboa: Instituo Nacional de Saúde Dr. Ricardo Jorge. Observatório Nacional de Saúde, 2005.

Ferreira, P.L. (1998). A medição do estado de saúde: criação da versão portuguesa do MOS SF-12. Coimbra: Centro de Estudos e Investigação em Saúde. Universidade de Coimbra.

Maryon-Davis, A., Stewart, L. (2005). Hypertension - the 'Silent Killer' Faculty of Public Health, London.

Macedo, M. E., Maria, J. L., Silva, A.O., Alcântara, P., Ramalhinho, V., \& Carmona, J. (2007). Prevalência, Conhecimento, Tratamento e Controlo da Hipertensão em Portugal. Estudo PAP. Revista Portuguesa de Cardiologia; 26 (1):21-39.

Oliveira Frédéric, M. de., Pereira, T., Pocinho, M., Figueiredo, J., \& Conde, J. (2007). Pressão Arterial e Fatores de Risco Cardiovascular: Estudo de uma amostra do concelho de Coimbra. Federación Argentina de Cardiologia.

Simões, C., Coelho, P., Alexandre, P., \& Pereira, T. (2011). Prevalência de Hipertensão Arterial na Cidade de Castelo Branco. Revista Portuguesa de Hipertensão e Risco Cardiovascular; 21:10-18. ISSN 1646-8287.

Perdigão, C., Duarte, J.S., Rocha, E., Santos, A. (2009). Prevalência e caracterização da Hipertensão Arterial em Portugal. Implicações numa estratégia de Prevenção. Uma análise do Estudo AMALIA. Revista Fatores de Risco; 13:14-22.

Vaz, D., Santos, L., \& Carneiro, A. (2005). Fatores de Risco: Conceitos e Implicações Práticas, Revista Portuguesa de Cardiologia; 24(1):121-131.

Kim, K.I., Lee, J.H., Kim, C.H. (2012). Impaired health-related quality of life in elderly women is associated with multimorbidity: results from the Korean National Health and Nutrition Examination Survey. Gender Medicine; 9(5):309-318. doi: 10.1016/j.genm.2012.08.001.

Gargano, J.W., \& Reeves, M.J. (2007). Sex differences in stroke recovery and stroke-specific quality of life: results from a statewide stroke registry. Stroke 38:2541-2548. 